\title{
SEQ: Suitability Evaluation Questionnaire for Virtual Rehabilitation Systems. Application in a Virtual Rehabilitation System for Balance Rehabilitation.
}

\author{
José-Antonio Gil-Gómez ${ }^{1}$ \\ Herme Gil-Gómez ${ }^{1}$, José-Antonio Lozano-Quilis ${ }^{1}$ \\ ${ }^{1}$ Instituto Universitario de Automática e Informática \\ Industrial, Universitat Politècnica de València, \\ C. Vera s/n, Valencia, SPAIN
}

\author{
Pilar Manzano-Hernández $z^{2}$ \\ Sergio Albiol-Pérez ${ }^{3}$, Carmen Aula-Valero², \\ ${ }^{2}$ Hospital S. José, Av. Zaragoza 16, Teruel, SPAIN \\ ${ }^{3}$ Dpto. de Informática e Ingeniería de Sistemas \\ Universidad de Zaragoza, C. Escolar s/n, Teruel, SPAIN
}

\begin{abstract}
Usability, acceptance and security of use are key factors in the validation of Virtual Rehabilitation system. Current literature offers different questionnaires for this purpose, but many of them do not consider some important issues and other are inadequate for patients. In this paper, we present SEQ (Suitability Evaluation Questionnaire) a novel questionnaire designed specifically for Virtual Rehabilitation systems. SEQ is based on a questionnaire with proven efficacy (SFQ) but with new questions that cover fundamental items not covered by SFQ. SEQ is an easy to understand questionnaire, with an affordable number of questions (14), which is being currently validated. This contribution presents also the study that is being carried out, and the preliminary results obtained from patients who have already completed the study $(\mathrm{N}=13)$. These initial results show an acceptable internal consistency of SEQ. As a secondary result, this contribution also indicates initial suitability evaluation of a Virtual Rehabilitation system designed for balance recovery.
\end{abstract}

Keywords: Suitability, usability, acceptance, questionnaire, virtual rehabilitation.

\section{INTRODUCTION}

Integration of technology in rehabilitation has led to the appearance of Virtual Rehabilitation (VR). VR offers great advantages for both patients and specialists. Current VR systems help clinical specialists, generating objective data and providing enjoyable rehabilitation to patients. Also, VR systems allow the efficient rehabilitation of more patients with lower total cost [1]. The playful approach frequently associated to VR systems and the integrated technology improves patient's experience, increasing motivation and adherence to the treatment. This bigger motivation results in better motor and psychological recovery [2], [3].

Clinical validity of VR systems has been demonstrated in many studies. Most of these studies conclude that the recovery of patients that follow a VR based program is greater than the recovery with traditional rehabilitation programs [4], [5].

Usually, these systems probe their clinical efficacy Vs traditional rehabilitation, but it is necessary to ensure first their adequacy in aspects such as usability, acceptance and security.

\section{RELATED WORK}

The importance of usability, acceptance and security of use in VR systems, has been previously indicated by many authors. Thus, the current background offers us various studies on VR systems that evaluate almost some of these items.

Fitzgerald et al. [6] carry out a usability evaluation of a VR system. This evaluation is done with VRUSE [7], a computerized usability questionnaire designed for Virtual reality applications. This questionnaire is very complete but it has an important problem: the great number of questions included. VRUSE is composed of 100 questions, too many questions especially considering that VR systems are targeted to patients, most of them with cognitive or attentional problems [8].

In [9], authors carried out an assessment of the usability of the Nintendo Wii Fit Plus for virtual reality rehabilitation of balance. To evaluate usability, Meldrum et al. uses the System Usability Scale (SUS) [10]; SUS has a limited number of questions (only 10), which is very appropriate for patients. On the other hand, SUS is too general, because it is designed to test hardware, cell-phones, websites... and also it is a usability scale that not consider adequately problems frequently associated with virtual reality systems, such us dizziness or nausea.

In other studies, many authors presented different questionnaires to evaluate the subjective responses of the patients to their specific VR systems [11], [12].

Among these questionnaires we find especially interesting the questionnaire presented by Kizony et al. in [13], the Short Feedback Questionnaire (SFQ). SFQ is based in Witmer and Singer's Presence Questionnaire [14]; SFQ consists in eight questions graded on a 5-point Likert scale. Authors demonstrated the suitability of this questionnaire to various virtual environments and with different clinical populations [15]. Also, Kizony and colleagues applied successfully SFQ for testing some of their systems [16]. 


\section{Suitability Evaluation Questionnaire (SEQ)}

Based on SFQ, we present in this contribution SEQ (see Table I), designed especially to test VR systems. Basically, SEQ extends SFQ, including questions to get responses for patients in specific items related with VR

SEQ includes 14 questions, 13 of them with a response graded on a 5-point Likert Scale, and a last open question. Following the SFQ scheme, the first seven questions measure enjoyment, sense of being in the system, feeling of success and control, realism, easy-to-understand instructions and general discomfort.

After, four new questions (Q8-Q11) are included to detect issues frequently associated with virtual rehabilitation systems: dizziness or nausea symptoms, eye discomfort, disorientation or confusion symptoms and sense of progress in rehabilitation.

These first eleven questions are graded from "Not at all" to "Very much".

The last two 5-point Likert scale questions are focused on difficulty: Q12 evaluates the perceived difficulty of the task (as the last question of the SFQ) and Q13 evaluate the observed difficulty related with the physical interface used in the system. Q12 and Q13 are graded from "Very easy" to "Very difficult".

The global score of SEQ ranges from 13 (poor suitability) to 65 (excellent suitability). In their calculation it is necessary to consider that items Q7, Q8, Q9, Q10, Q12 and Q13 are negative items (that is, a response of 1 has a value of 5 , a response of 2 has a value of $4, \ldots)$.

Finally, an open question (Q14) asks patients if they felt uncomfortable, requesting the reasons why.

The questionnaire has a convenient number of questions (14), enough to measure the suitability of the system but not too many for the patients. Questions are direct and clear, and SEQ also takes into account issues concerning VR system.

\section{STUDY DESIGN}

We are now developing a study to validate the suitability of SEQ for VR systems. The study is currently a work in progress, but we present here the study design and also the first results.

\section{A. Participants}

Fifty patients $(\mathrm{N}=50)$ will be considered in the program.

The inclusion criteria are 1) signed written informed consent before the study, 2) age $>17$ years and $<90$ years, 3) evidence of balance problems quantified by clinical balance scales, 4) absence of cognitive impairment (Mini-mental State Examination [17] >23), 5) able to follow instructions.

The exclusion criteria are 1) dementia, 2) visual deficit, 3) hemispatial neglect, 4) clinical instability, 5) unsolved acute trauma injury, 6) severe hearing impairment and 7) birth injury.

Currently, a total of 13 patients have completed the SEQ evaluation. Diagnosis of these patients includes Parkinson disease, Guillain-Barré syndrome, brain tumor, vestibular pathology, cervical joint degeneration, multiple sclerosis, meningioma, subdural hematoma, stroke and cervical myelopathy. The 13 patients who have currently completed the study included 7 men and 6 women, ranging from 33 to 85 years old $(63.5 \pm 18.5)$.

\section{B. Study interventions}

In this study, SEQ is used to test the suitability of ABAR (Active Balance Rehabilitation) system. ABAR system is a VR system designed to rehabilitate balance problems in patients with different etiology, such as Parkinson Disease [18], stroke or Guillain-Barré syndrome.

ABAR facilitates different games designed in collaboration with clinical specialist to recover static and dynamic balance.

TABLE I. SUITABILITY EVALUATION QUeSTIONNAIRE (SEQ)

\begin{tabular}{|c|c|c|c|c|c|}
\hline \multirow{2}{*}{ Question } & \multicolumn{5}{|c|}{ Response } \\
\hline & Not at all & & & & Very much \\
\hline Q1. How much did you enjoy your experience with the system? & 1 & 2 & 3 & 4 & 5 \\
\hline Q2. How much did you sense to be in the environment of the system? & 1 & 2 & 3 & 4 & 5 \\
\hline Q3. How successful were you in the system? & 1 & 2 & 3 & 4 & 5 \\
\hline Q4. To what extent were you able to control the system? & 1 & 2 & 3 & 4 & 5 \\
\hline Q5. How real is the virtual environment of the system? & 1 & 2 & 3 & 4 & 5 \\
\hline Q6. Is the information provided by the system clear? & 1 & 2 & 3 & 4 & 5 \\
\hline Q7. Did you feel discomfort during your experience with the system? & 1 & 2 & 3 & 4 & 5 \\
\hline Q8. Did you experience dizziness or nausea during your practice with the system? & 1 & 2 & 3 & 4 & 5 \\
\hline Q9. Did you experience eye discomfort during your practice with the system? & 1 & 2 & 3 & 4 & 5 \\
\hline Q10. Did you feel confused or disoriented during your experience with the system? & 1 & 2 & 3 & 4 & 5 \\
\hline \multirow[t]{2}{*}{ Q11. Do you think that this system will be helpful for your rehabilitation? } & 1 & 2 & 3 & 4 & 5 \\
\hline & Very easy & & & & $\begin{array}{c}\text { Very } \\
\text { difficult }\end{array}$ \\
\hline Q12. Did you find the task difficult? & 1 & 2 & 3 & 4 & 5 \\
\hline Q13. Did you find the devices of the system difficult to use? & 1 & 2 & 3 & 4 & 5 \\
\hline Q14. If you felt uncomfortable during the task, please indicate the reasons. & & $\mathrm{n} r$ & Jo) & eas & \\
\hline
\end{tabular}


TABLE II. ABAR GAMES

SITTING POSITION
Game objective
With their weight transferences, the
patient moves the ladybug to catch the
candy.
With medio-lateral weight
transferences, the patient moves the car
to get petrol. The horizontal position of
the car is discrete: there are 3 different
positions.
STANDING POSITION
horizontal position of the car is
on the screen there are 3 different positions.
The patient moves the boat from left to
right recueing swimmers. The
horizontal position of the boat is
continuous.
The patient moves the bee up and
down to get the flower.
The patient moves the lightbeam up
and down to catch the thief.

ABAR uses the Nintendo ${ }^{\circledR}$ Wii Balance Board ${ }^{\circledR}$ (WBB) for the interaction patient-system. WBB is a low cost device used in many VR systems to obtain the center-of-pressure (COP) of the patient.

Table II summarize the aim of the games, with screenshots.

\section{Study procedures}

The study is being carried out in a specialized rehabilitation service of a metropolitan hospital. Each patient complete 20 ABAR sessions of 30 minutes each with 3-5 sessions per week (see Fig 1).

In the study, clinical assessment is done before and after the rehabilitation program, and also one month after the end of the program (follow-up evaluation). SEQ is completed immediately after the first session with ABAR.

\section{Outcome measures}

For this study SEQ provides the primary outcome measures. With these measures we want to test the internal

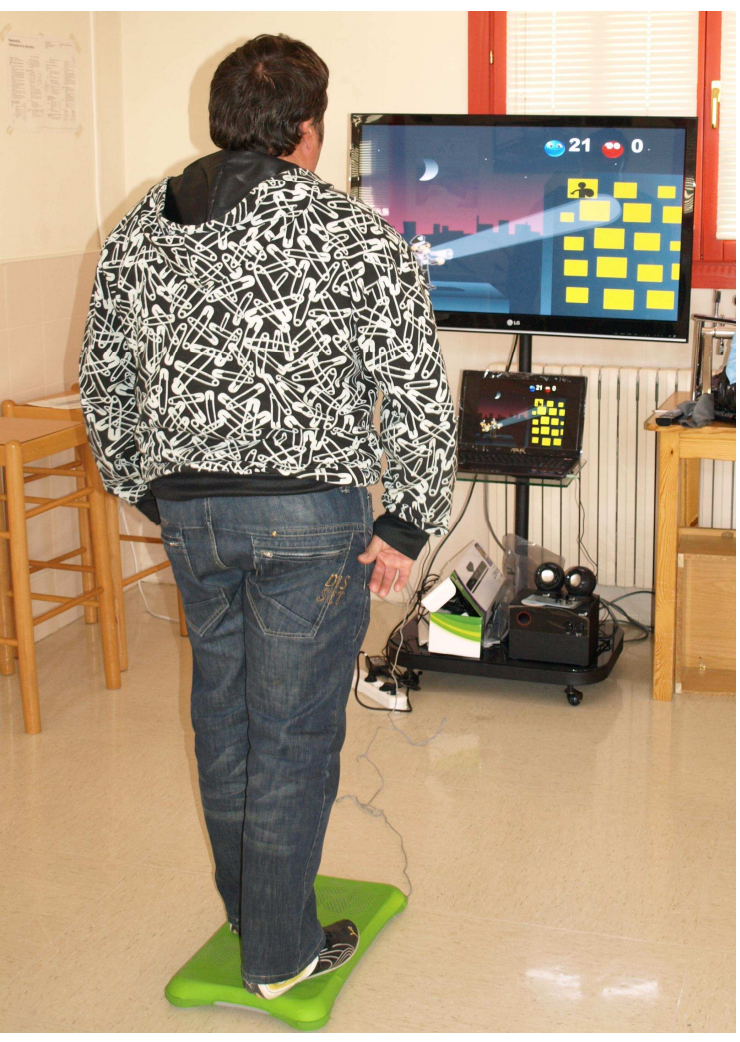

Fig. 1. Patient using ABAR system.

consistency reliability of SEQ to ensure the reliability of the questionnaire.

Out of the main objective of this work, there are other outcome measures, such as clinical measures, to quantify the clinical efficacy of ABAR. Clinical condition is assessed by Anterior Reach Test [19], Unipedal Stance Time [20], Berg Balance Scale test [21], Tinetti Test [22], Time "Up and Go" Test [23], Timed 10-Meter Walking Test [24], and 30-second Sit-to-Stand Test [25].

\section{RESULTS}

Currently, only thirteen patients have completed SEQ. This value is not enough to evaluate adequately the internal consistency of the questionnaire, but initial results are very promising. Initial results showed an acceptable internal consistency reliability of SEQ (Cronbach's alpha $=0.7$ ).

Relating suitability of ABAR system, SEQ shows very good results (see Table 3). The global score ranged from 44 to 60 with a mean score of 54.85 (normalized suitability score, mean $\pm \mathrm{SD}=0.80 \pm 0.01)$. Relating particular items, patients enjoyed the system $(\mathrm{Q} 1$, mean $\pm \mathrm{SD}=4.54 \pm 0.66)$, they did not felt confused or disoriented $(\mathrm{Q} 8$, mean $\pm \mathrm{SD}=1.23 \pm 0.60)$ and patients thought that ABAR will be helpful for their rehabilitation $(\mathrm{Q} 11$, mean $\pm \mathrm{SD}=4.08 \pm 0.76)$.

Only one of the thirteen patients felt uncomfortable due to neck pain, but the patient experienced this pain also in other cases. 
TABLE III. MEAN AND SD (STANDARD DEVIATION)

\begin{tabular}{|l|cc|}
\hline \multicolumn{1}{|c|}{ Question } & \multicolumn{2}{c|}{ Result (N=13) } \\
\cline { 2 - 3 } & Mean & SD \\
\hline Q1. How much did you enjoy your experience with... & 4.54 & 0.66 \\
\hline Q2. How much did you sense to be in the ... & 3.00 & 1.63 \\
\hline Q3. How successful were you in the system? & 4.08 & 0.95 \\
\hline Q4. To what extent were you able to control the system? & 3.92 & 0.95 \\
\hline Q5. How real is the virtual environment of the system? & 3.31 & 1.38 \\
\hline Q6. Is the information provided by the system clear? & 4.62 & 0.87 \\
\hline Q7. Did you feel discomfort during your experience... & 1.54 & 0.78 \\
\hline Q8. Did you experience dizziness or nausea during ... & 1.23 & 0.60 \\
\hline Q9. Did you experience eye discomfort during your... & 1.31 & 0.48 \\
\hline Q10. Did you feel confused or disoriented during... & 1.15 & 0.55 \\
\hline Q11. Do you think that this system will be helpful for ... & 4.08 & 0.76 \\
\hline Q12. Did you find the task difficult? & 1.92 & 0.95 \\
\hline Q13. Did you find the devices of the system difficult ... & 1.54 & 0.66 \\
\hline GLOBAL SCORE (total) & 54.85 & 28.64 \\
GLOBAL SCORE (normalized) & 0.80 & 0.01 \\
\hline
\end{tabular}

\section{DISCUSSION AND CONCLUSIONS}

This paper introduces SEQ, a novel questionnaire designed specifically for VR systems. SEQ is based on a questionnaire with proven efficacy and with good internal consistency reliability (SFQ) but covering other fundamental items not covered by SFQ.

SEQ is an easy to understand questionnaire, with an affordable number of questions (14) that is currently being validated.

Data obtained from patients who have currently completed SEQ $(\mathrm{N}=13)$ shows an acceptable internal consistency.

A secondary result of the study is related with the suitability of ABAR system. Preliminary results $(\mathrm{N}=13)$ confirmed very good results for most of the SEQ questions.

\section{ACKNOWLEDGEMENTS}

Authors would like to thank patients and clinical specialists from S. José Hospital for their suggestions and collaborations.

\section{REFERENCES}

[1] J.H. Annema, M. Verstraete, V.V. Abeele, S. Desmet and D. Geerts. "Videogames in therapy: a therapist's perspective.", 2010.

[2] E.M Pereira, F.M., Rueda, I.A. Diego and R.C. Cuerda. "Empleo de sistemas de realidad virtual como método de propiocepción en parálisis cerebral: guía de práctica clínica. Neurología.”, 2012.

[3] K. Laver, S. George, S., Thomas, J. Deutsch, J., \& Crotty, M. (2011). Virtual reality for stroke rehabilitation (Review). The Cochrane Library, Issue 9.

[4] J.A. Gil-Gómez, R. Lloréns, M. Alcañiz and C. Colomer, "Effectiveness of a Wii balance board-based system (eBaViR) for balance rehabilitation: a pilot randomized clinical trial in patients with acquired brain injury," J Neuroeng Rehabil, vol. 23, 2011.

[5] G. Brichetto, P. Spallarossa, M.L. Lopes-de-Carvalho, and M.A. Battaglia, "The effect of Nintendo ${ }^{\circledR}$ Wii ${ }^{\circledR}$ on balance in people with multiple sclerosis: a pilot randomized control study," Multiple Sclerosis Journal, 2013.
[6] D. Fitzgerald, D. Kelly, T. Ward, C. Markham and Brian Caulfield, "Usability Evaluation of E-Motion: A Virtual Rehabilitation System Designed to Demonstrate, Instruct and Monitor a Therapeutic Exercise Programme", Virtual Rehabilitation, pp. 144-149. 2008.

[7] R. S. Kalawsky, "VRUSE-a computerised diagnostic tool: for usability evaluation of virtual/synthetic environment systems", Applied Ergonomics, Vol. 30, pp. 11-25, 1999.

[8] J. M. McDowd, D. L. Filion, P. S. Pohl, L. G. Richards, and W. Stiers, "Attentional abilities and functional outcomes following stroke," J Gerontol B Psychol Sci Soc Sci 58 (1), P45-53, 2003.

[9] D. Meldrum, A. Glennon, S. Herdman, D. Murray, and R. McConnWalsh, "Virtual reality rehabilitation of balance: assessment of the usability of the Nintendo Wii((R)) Fit Plus," Disabil Rehabil Assist Technol 7 (3), 205-210, 2012.

[10] J. Brooke. SUS: A "quick and dirty" usability scale. In: Jordan PW, Thomas B, Weerdmeester BA, McClelland AL, editors. Usability evaluation in industry. London: Taylor and Francis. pp 189-194, 1996

[11] M. S. Cameirao, S. B. Badia, E. D. Oller, and P. F. Verschure, "Neurorehabilitation using the virtual reality based Rehabilitation Gaming System: methodology, design, psychometrics, usability and validation," J Neuroeng Rehabil 7, 48, 2010.

[12] H. Regenbrecht, S. Hoermann, G. McGregor, B. Dixon, E. Franz, C. Ott, L. Hale, T. Schubert, and J. Hoermann, "Visual manipulations for motor rehabilitation," Computer \& Graphics 36 (7), 819-834, 2012.

[13] R. Kizony, N. Katz, and P.L. Weiss, "Adapting an immersive virtual reality system for rehabilitation," The Journal of Visualization and Computer Animation 14 (5), 261-268, 2003.

[14] B.G. Witmer, and M.J. Singer. "Measuring Presence in Virtual Environments: A Presence Questionnaire", Presence: Teleoperators and Virtual Environments, 7(3), 225-240, 1998.

[15] R. Kizony, N. Katz, D. Rand and P.L. Weiss, "A Short Feedback Questionnaire (SFQ) to enhance client-centered participation in virtual environments". 11th Annual Cyber Therapy Conference: Virtual Healing: Designing Reality, Gatineau, Canada. 2006.

[16] R. Kizony, L. Raz, N. Katz, H. Weingarden and P.L. Weiss, "Using a video projected VR system for patients with spinal cord injury," Journal of Rehabilitation Research \& Development, 42, pp. 595-608, 2005.

[17] M.F. Folstein, S. Folstein and P.R. Mchugh, "Mini-Mental State: a practical method for grading the cognitive state of patients for the clinicians". J Psychiatr Res, 12(3):189-198. 1975.

[18] S. Albiol-Pérez, J.A. Lozano-Quilis, H. Gil-Gómez, J.A. Gil-Gómez and R. Llorens, "Virtual rehabilitation system for people with Parkinson's disease," 9th international conference on disability, virtual reality and associated technologies (ICDVRAT), pp. 423-427, 2012.

[19] P.W. Duncan, D.K. Weiner, J. Chandler and S. Studensk,"Functional reach: a new clinical measure of balance," J Gerontol 1990, vol. 45, pp. 192-197, 1990.

[20] G.P. Austin, D. Tiberio and G.E. Garrett, "Effect of frequency on human unipedal hopping," Percept Mot Skills, vol. 95, pp. 733-40, 2002.

[21] K.O. Berg and S.L. Wood-Dauphinee, J.I. Williams and B. Maki, "Measuring balance in the elderly: validation of an instrument," Can J1 of Public Health, vol. 83, pp. 7-11, 1992.

[22] M.E. Tinetti, T.F. Williams and R. Mayewski, "Fall risk index for elderly patients based on number of chronic disabilities," Am J Med, 80(3), pp. 429-34, 1986.

[23] D. Podsiadlo and S. Richardson, "The time "up \& go": a test of basic functional mobility for frail elderly persons," J Am Geriatr Soc, vol. 39, pp. 142-148, 1991.

[24] V.A. Scholtes et al., "Lower limb strength training in children with cerebral palsy - a randomized controlled trial protocol for functional strength training based on progressive resistance exercise principles," BMC Pediatr, 8, pp. 8:41, 2008.

[25] S. O'Shea, N. Taylor and J. Paratz, "Reliability of hand-held dynamometry and functional strength tests for the lower extremity in children with cerebral palsy," Arch Phys Med Rehabil, 88(1), pp. 32-36, 2007. 